\title{
Optimization of Reinforced Concrete Column Using Android- based Mobile Application
}

\author{
Johan Lautan Wijaya Nusantara ${ }^{1, *}$, Akhmad Aminullah ${ }^{2}$, and Andreas Triwiyono ${ }^{2}$ \\ ${ }^{1}$ Master Student of Department of Civil and Environmental Engineering, Universitas Gadjah Mada, Indonesia \\ ${ }^{2}$ Lecturer of Department of Civil and Environmental Engineering, Universitas Gadjah Mada, Indonesia
}

\begin{abstract}
Reinforced concrete column has complicated calculations. Designer usually acts trial and error to get the optimum dimension and reinforcement according to the occurred loads. It takes long process and the result is not always be the most economical section. Nowadays smartphone with its various applications is very popular among societies. Besides being more flexible in place and time, smartphone has ease in operation and is commonly used by people. Hence, those advantages can be used to optimize reinforced concrete column quickly and accurately. The application named " $\mathrm{C}^{2} \mathrm{App}$ " (Concrete Column Application) had been created by accommodate regulation in Indonesia (SNI 2847:2013). Biaxial calculation used Bresler's approach, while calculation of slender column applied Moment Magnification Method. The application is able to show interaction diagram, section drawing, and result tables. Moreover, the application was equipped with local database, and detailed calculations in pdf format to support the real project. Validation was done with computer-based software named CSiCol and ASDIP Concrete, whereas the optimization result was compared with other designs which used ACI Diagrams and Particle Swarm Optimization method. The application was pretty accurate and could provide a more economical section.
\end{abstract}

\section{Introduction}

Column is an important component in framed structure. Failure of the column may lead the whole building to be collapse. Thus, column failure should be prevented by performing a good column design.

Reinforced Concrete (RC) column has complex calculation to create an interaction diagram. Furthermore the applied load can be plotted into the diagram to find out whether the capacity of the used cross section meets the requirements. Designer usually acts trial and error to get the safe section which is able to resist the loads. It takes long process and the result is not always be the most economical section.

The role of a structural engineer is designing a safe and economical structure [1]. Therefore, it is necessary to optimize the dimension and the reinforcement of column in order to get the appropriate design section. RC column optimization takes safety, and minimum total cost of the materials that consist of concrete and reinforcement. Since column is an important part of framed structure, optimization of the column can reduce the total cost of the building [2]. It should be considered that in case of RC structure, the minimum weight design is not always directly proportional to the minimum cost of design. The reinforcement is more expensive than concrete, so it needs an optimization to get the right combination [3].

Efficient optimization with complex calculations requires the right program [4]. Nowadays, smartphone with Android operating system has been developed rapidly among societies. Android-based smartphone had been chosen to optimize the RC column. It is very suitable to use because of its ease and the speed of operation. Its use is very flexible and easy to learn by people. Other than that public is more familiar with Android-based smartphone compared to computers which has been commonly used by engineers. Although it looks so simple, this can be used as a preliminary estimate than can be obtained quickly. Nevertheless, there was no mobile application which supported it. In this paper, it had been developed an Android based application that can be used to optimize RC column. The built application can do the calculation of uniaxial, and biaxial for rectangular or circular column in short or slender condition.

In general, almost all researches on RC column optimization provide graphs or tables that can be used in the design. Those can reduce the calculation time, but it is difficult to get the right conditions according to the existing tables and graphs. In addition, not all variable values are available in the graphs and tables, so it needs to be interpolated to get the right result from desired

* Corresponding author: johanlautan5@gmail.com 
variable. By using android-based application, those variable values can be inputted as desired so that its use is more flexible and faster.

\section{Literatures}

Many researches on design and optimization of RC column using certain software or method had been developed before. Mahamida, and Houshiarb [5] had developed computer program using Direct Method with minimum reinforcement required for short column without using interaction diagram. The resulted graph was capable to show the suitable columns. Rafiq, and Southcombe [6] had developed a computer program using Genetic Algorithms (GAs) method to optimize biaxial column economically. Sanchez-Olivares, and Tomas [4] had used Biologically-Inspired-Meta-heuristic optimization algorithms in the design of rectangular RC column at the minimum cost. Tapao, and Cheerarot [7] had applied Artificial Bee Colony (ABC) algorithms to optimize the design of RC structures including column. Dalton, Atamturktur, Farajpour, and Juang [1] had optimized RC columns based on safety, robustness, and cost using Particle Swarm Optimization Method. Medeiros, and Kripka [8] did the optimization of rectangular RC column using Harmony Search Algorithm method.

Aschheim, Montes, and GilMartin [9] had combined Conjugate Gradient Search Method in the general model for rectangular $\mathrm{RC}$ column optimization. Thomas, and Arulraj [10] had optimized the design of uniaxial column by using Matlab which was formulated as Nonlinear Constrained. Singh, and Chutani [2] had carried out the column optimization with Direct Search Method. Gare, and Seyan [11] had investigated the optimum design based on minimum cost using Ms. Excel and generated some referenced graphs.

Guerra, and Kiousis [12] had used SQP Algorithm which was implemented in Matlab. Jabbar [13] had optimized the cost of short column with parameters of concrete, reinforcement, and formwork. Regupathi [3] had developed Hybrid Genetic Algorithm in optimizing the cost of multistory frame.

\section{Equations}

\subsection{Axial and Bending Analysis}

Internal force on the concrete can be calculated by using Equivalent Stress Block [14].

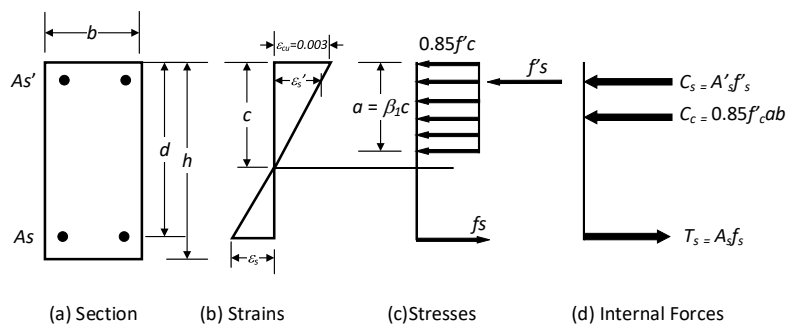

Fig. 1. Equivalent Stress Block source: Reinforced Concrete Mechanics and Design [15]

Force which is acting on the concrete is formulated as follow :

$$
C_{c}=0.85 f^{\prime}{ }_{c} b a
$$

where $a=\beta_{1} c$

Value of $\beta_{l}$ can be calculated with this formula

$$
\begin{array}{ll}
\beta_{1}=0.85 & \text { for } f^{\prime}{ }_{c} \leq 28 \mathrm{MPa} \\
\beta_{1}=0.85-0.05\left(\frac{f^{\prime} c-28}{7}\right) & \text { for } f^{\prime}{ }_{c}>28 \mathrm{MPa}
\end{array}
$$

The moment capacity which is contributed by the concrete is formulated as follow :

$$
M_{c}=C_{c}\left(\frac{h-a}{2}\right)
$$

The strain at the cross section applies Bernoulli's theorem with ultimate strength is determined at maximum compressive strain of 0.003 [9]. So the strain on the steel can follow the equation :

$$
\varepsilon=\frac{c-d}{c} 0.003
$$

While the forces that acting on the reinforced steel is formulated as follows :

$$
F_{s}=A_{s} f_{y} \text { for }\left|\varepsilon_{s}\right| \geq \varepsilon_{y}
$$

where $\varepsilon_{y}=\frac{f_{y}}{E_{s}}$

$$
F_{s}=A_{s} f_{s} \text { for }\left|\varepsilon_{s}\right|<\varepsilon_{y}
$$

where $f_{s}=\varepsilon_{s} E_{s}$

The moment capacity which is contributed by the reinforcement is formulated as follow

$$
M_{s}=F_{s}\left(\frac{h}{2}-d\right)
$$

The axial and bending capacity of the column is formulated as follows :

$$
\begin{aligned}
& \phi P_{n}=\phi\left(C_{c}+F_{s}\right) \\
& \phi M_{n}=\phi\left(M_{c}+M_{s}\right)
\end{aligned}
$$

The maximum compressive strength which can be supported by a column is formulated as follows : for spiral :

$$
\phi P_{n(\max )}=0.85 \phi\left[0.85 f_{c}^{\prime}\left(A_{g}-A_{s t}\right)+f_{y} A_{s t}\right]
$$

for stirrup-tie :

$$
\phi P_{n(\max )}=0.80 \phi\left[0.85 f^{\prime}{ }_{c}\left(A_{g}-A_{s t}\right)+f_{y} A_{s t}\right]
$$

The reduction factor $(\phi)$ is determined based on the occurred strain of the outer steel [16]. 


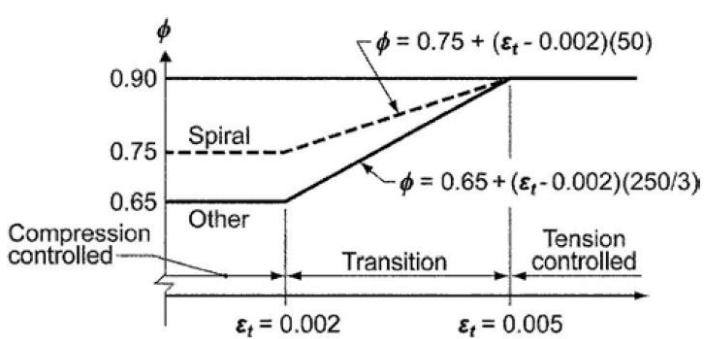

Fig. 2. Reduction Factor $(\phi)$ source: Building Code [17]

\subsection{Biaxial Analysis}

Bresler suggested a relationship of $\mathrm{X}$-direction and $\mathrm{Y}$ direction interaction diagram is considered as a curve and following the equation

$$
\left(\frac{M_{u x}}{M_{o x}}\right)^{\alpha}+\left(\frac{M_{u y}}{M_{o y}}\right)^{\alpha} \leq 1
$$

This method is also known as "Load Contour Method".

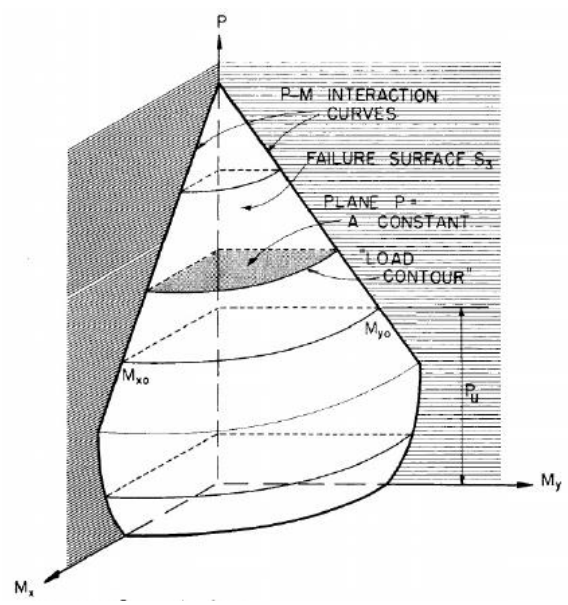

Fig. 3. Load Contour

source: Design Criteria for Reinforced Columns under Axial Load and Biaxial Bending [18]

Exponent $\alpha$ is influenced by the dimensions, the number and configuration of the reinforcement and concrete, the concrete cover, and also the tied. The value of exponent $\alpha$ ranges from 1.0 to 2.0 , where the result is obtained through the equation [19]:

$$
\alpha=1.66 \frac{P_{u}}{P_{o}}+0.67
$$

\subsection{Moment Magnification}

The considerations in RC column calculation are not only based on the load $\left(P_{u}-M_{u x}-M_{u y}\right)$, but also should consider the possibility of buckling failure. The applied moments can cause lateral displacement and give additional moments.

The moment magnification factor is divided into two, they are non-sway frame and sway frame [16]. Column can be classified into non-sway frame when it meets the requirement :

$$
\frac{k l_{u}}{r} \leq 34-12\left(\frac{M_{1}}{M_{2}}\right) \leq 40
$$

then the magnification factor is :

$$
\delta_{n s}=\frac{C_{m}}{1-\frac{P u}{0.75 P_{c}}} \geq 1.0
$$

Column can be classified into sway frame when it meets the requirement :

$$
\frac{k l_{u}}{r} \leq 22
$$

then the magnification factor is :

$$
\delta_{s}=\frac{1}{1-\frac{\sum P_{u}}{0.75 \sum P_{c}}} \geq 1.0
$$

\subsection{Optimization}

Optimization is a branch of mathematic that concentrates on obtaining conditions that produce extreme values of the given state functions [3]. The functions of the situation to be achieved should obtain economical cross section of RC column that has sufficient capacity to resist the existing load. The load combination must be inside the interaction diagram to meet the requirements [20]. The total cost considered in this optimization is counted from the cost of the concrete and the reinforcement.

\section{Methods}

An Android application was created using a software named Android Studio. The application was built under the name " $\mathrm{C}^{2}$ App" (Concrete Column Application). This application can be set by user to get optimum cross section for rectangular, square or circular column as shown in Figure 4. The calculation of this optimization is based on the flowchart in Figure 10. In principle, the algorithm do the calculation of the safety of the RC column on every possible combination of column dimension, and reinforcement. The algorithm calculates the analysis of uniaxial, biaxial, and also considering the effect of slender column for rectangular, and circular column.
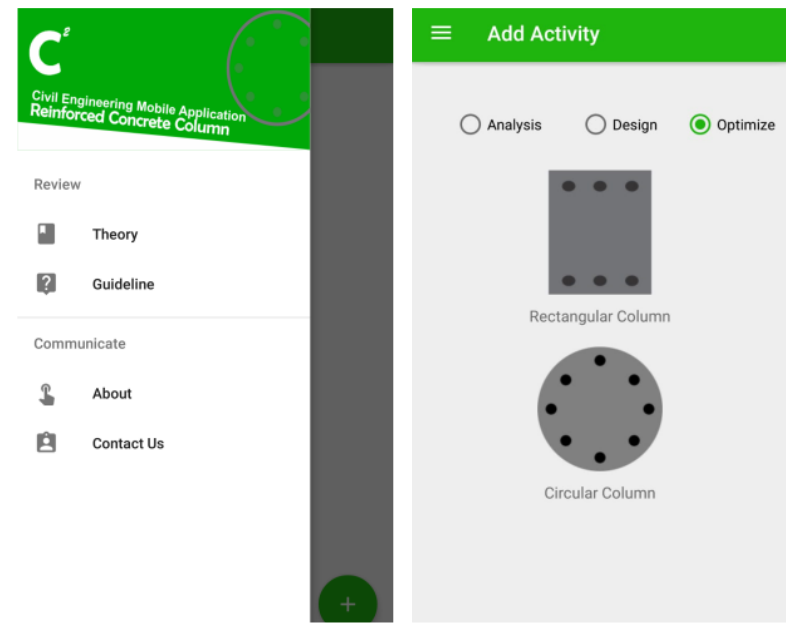

Fig. 4. $C^{2}$ App 

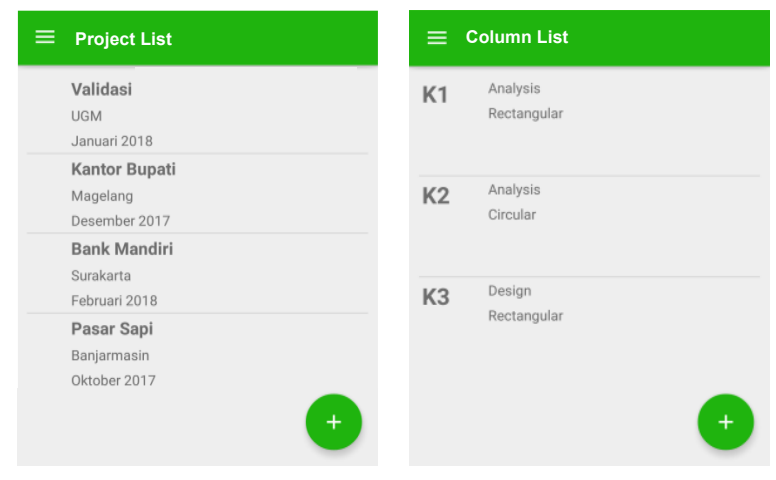

Fig. 5. $C^{2}$ List
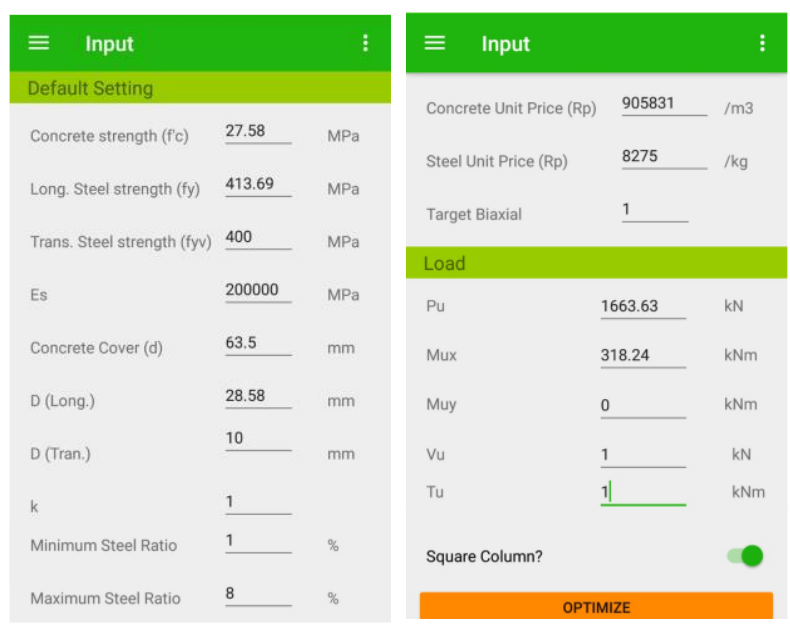

Fig. 6. $C^{2}$ App Input

The variable values can be inputted as continuous numbers according to the actual condition. Moreover, the desired reinforcement ratio can be set by the user. $C^{2} \mathrm{App}$ is also equipped by Local Database for project and column types, so that the values of the variables can be stored according to their identity. In supporting user interpretation, $\mathrm{C}^{2} \mathrm{App}$ also provides result tables, calculation detail in pdf format, and design drawing as shown in Figure 7 and 8.

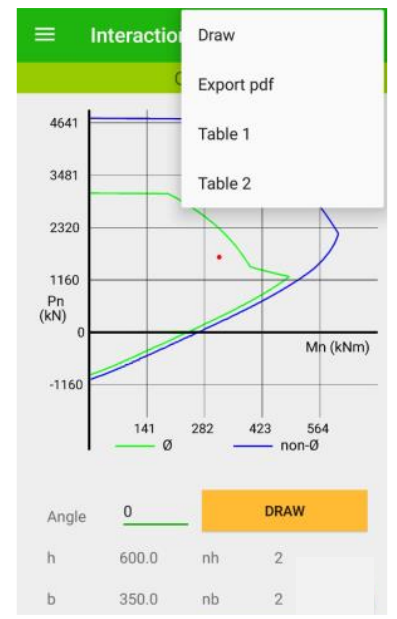

\begin{tabular}{|lllll|}
\hline$\equiv$ & \multicolumn{4}{l}{ Table Interaction } \\
\hline $\mathrm{c}(\mathrm{X})$ & $\mathrm{Pn}$ & $\mathrm{Mn}$ & $\emptyset \mathrm{Pn}$ & $\emptyset \mathrm{Mn}$ \\
\hline 30 & -852 & 60 & -767 & 54 \\
\hline 60 & -157 & 230 & -142 & 207 \\
\hline 90 & 293 & 336 & 264 & 303 \\
\hline 120 & 639 & 413 & 575 & 371 \\
\hline 150 & 929 & 471 & 836 & 424 \\
\hline 180 & 1193 & 517 & 1073 & 465 \\
\hline $\mathrm{c}(\mathrm{Y})$ & $\mathrm{Pn}$ & $\mathrm{Mn}$ & $\emptyset \mathrm{Pn}$ & $\emptyset \mathrm{Mn}$ \\
\hline 18 & -858 & 34 & -772 & 31 \\
\hline 35 & -643 & 67 & -579 & 60 \\
\hline 52 & -79 & 135 & -71 & 122 \\
\hline 70 & 348 & 185 & 313 & 167 \\
& & & & \\
\hline & & & & \\
\hline
\end{tabular}
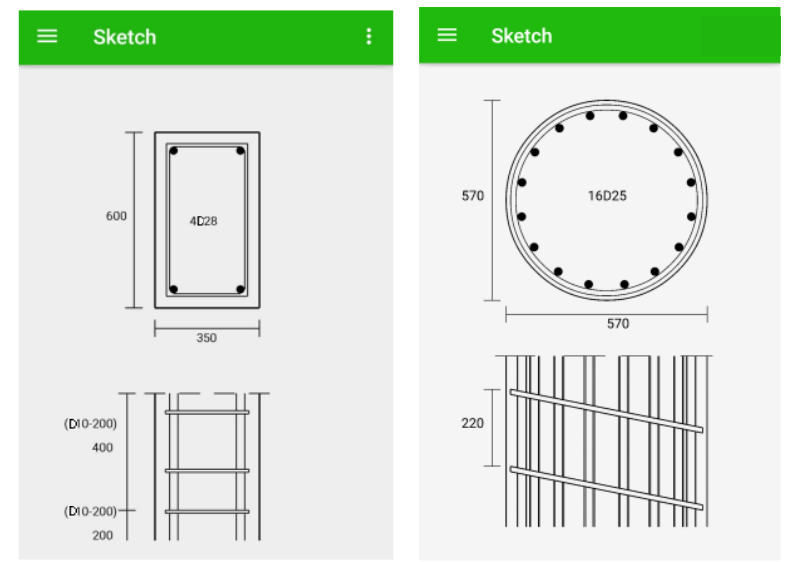

Fig. 8. $C^{2}$ App Design Drawing

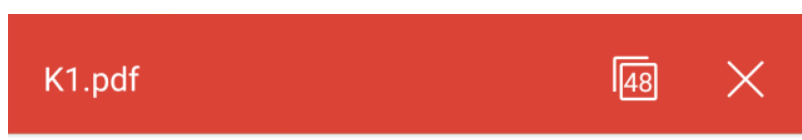

LAPORAN ANALISIS KOLOM BETON BERTULANG

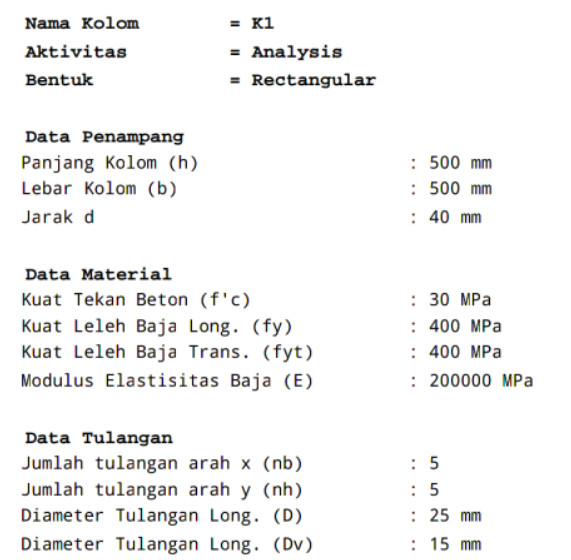

Fig. 9. pdf output

The smallest column dimension is started from the minimum required dimension to resist the pure axial force, while the reinforcement is limited by minimum and maximum reinforcement ratios. Thus the lower and upper limits of the reinforcement on each column dimension have different values.

First, column calculation is done by the smallest dimension of the column with the highest reinforcement ratio. The next calculation is executed with the same column dimension with reducing the reinforcement ratio up to the minimum ratio. After that, the dimension of the concrete is added with the same reinforcement setting as before.

In narrowing the scope of the count, some limitations are imposed as shown in the flowchart in Figure 10. Then, combination of concrete and reinforcement is chosen at the lowest total cost.

Fig. 7. $C^{2}$ App Output 


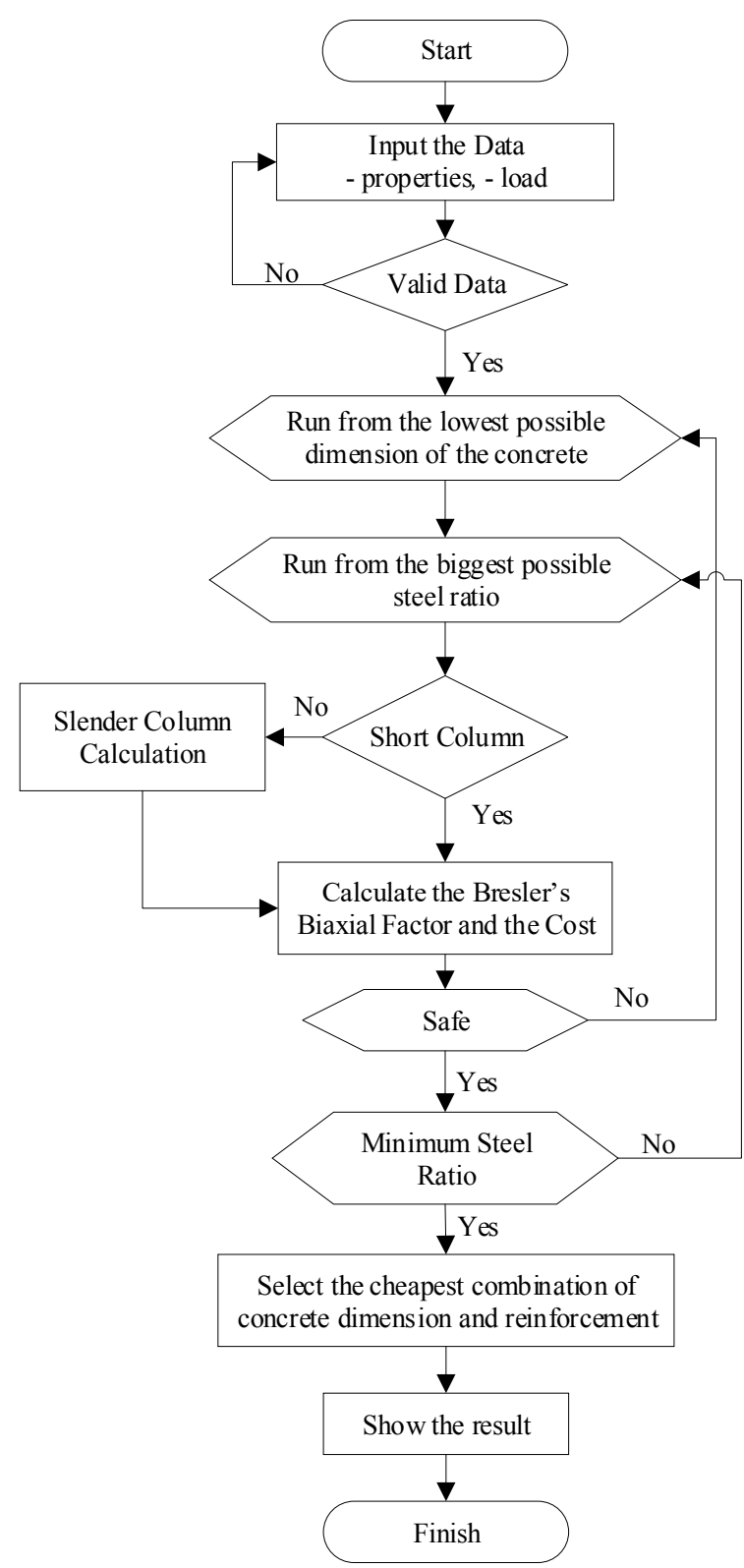

Fig. 10. Algorithm Flowchart

\section{Discussions}

\subsection{Validate with other softwares}

The built application need to be proven its validity so that the result can be a responsible calculation. Validation had been done by comparing the interaction diagram which was resulted by $\mathrm{C}^{2}$ App with other softwares those were ASDIP Concrete and CSiCol. ASDIP Concrete is a software which was produced by ASDIP Structural Software. That software can be used in RC analysis and design for column, beam, and bearing wall. CSiCol is one of the softwares produced by Computers and Structures Inc. which was designed specifically for RC column analysis.

\subsubsection{Rectangular Column}

Rectangular column validation was done by comparing the interaction diagram for a column with following specifications :

$f^{\prime}{ }_{c}=30 \mathrm{Mpa}, f_{y}=400 \mathrm{MPa}, E_{s}=200000 \mathrm{Mpa}$.

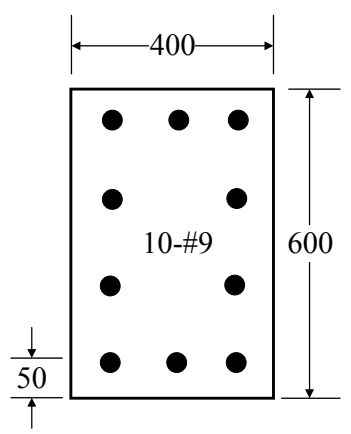

Fig. 11. Rectangular Column

Above column specifications was modeled by using CSiCol, ASDIP Concrete, and $\mathrm{C}^{2}$ App. Based on the result values in the interaction diagrams in $\mathrm{X}$-direction and $\mathrm{Y}$ direction of each softwares, then those values were superposed as shown in Figure 12. From the figure, it was shown that the interaction diagram of three softwares had the same pattern in $\mathrm{X}$-direction and $\mathrm{Y}$-direction. Furthermore, $\phi P_{n}$ and $\phi M_{n}$ values of three softwares were compared according to the eccentricity.

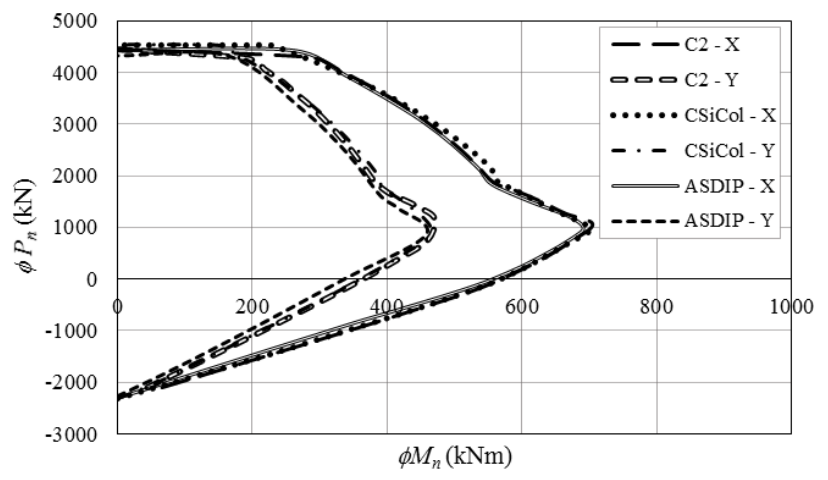

Fig. 12. Interaction Diagram for Rectangular Column

Based on values of $\phi P_{n}$ and $\phi M_{n}$ in the interaction diagram in Figure 12, it was gotten the maximum difference of $3.46 \%$ with CSiCol and $4.96 \%$ with ASDIP Concrete for $\mathrm{X}$-direction, while $4.37 \%$ with CSiCol and $3.77 \%$ with ASDIP Concrete for Y-direction.

\subsubsection{Circular Column}

Circular column validation was done by comparing the interaction diagram for a column with following specifications :

$f^{\prime}{ }_{c}=30 \mathrm{Mpa}, f_{y}=400 \mathrm{MPa}, E_{s}=200000 \mathrm{Mpa}$. 


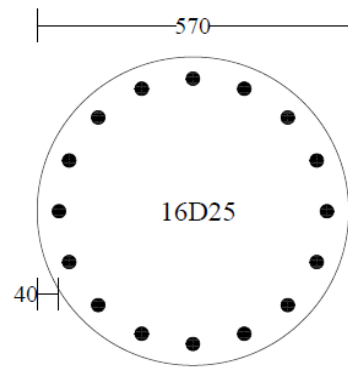

Fig. 13. Circular Column

Above column specifications was modeled by using CSiCol, ASDIP Concrete, and $\mathrm{C}^{2}$ App. Based on the result values in the interaction of each softwares, then those values were superposed as shown in Figure 14. From the figure, it was shown that the interaction diagram of three softwares had the same. Furthermore, $\phi P_{n}$ and $\phi M_{n}$ values of three softwares were compared according to the eccentricity.

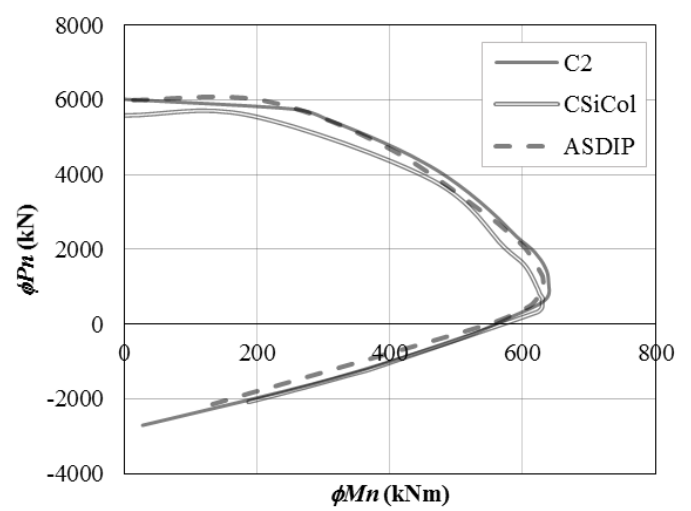

Fig. 14. Interaction Diagram for Circular Column

Based on values of $\phi P_{n}$ and $\phi M_{n}$ in the interaction diagram in Figure 14, it was gotten the maximum difference of $5.82 \%$ with CSiCol and $6.21 \%$ with ASDIP Concrete.

\subsection{Application Performance in Optimization}

Application for RC column optimization can be useful when its use is easy, fast, flexible, and able to provide a safe and economical cross-section of column. Level of ease, speed, and flexibility has been fulfilled with the use of mobile application. Whereas at the economical level, $\mathrm{C}^{2}$ App was compared with design results using ACI diagrams and calculations using Particle Swarm Optimization method. The unit price of concrete and steel reinforcement referred to the standard price of Government of Yogyakarta City 2017.

\subsubsection{ACl Diagrams}

ACI has provided normalized Interaction Curves on different cross-sections and reinforcement arrangements for different concrete and steel grades [20]. The use of those curves should be done manually and must adapt every grades of concrete, and steel.
In this paper, it had been compared seven columns designed by using ACI diagrams and $\mathrm{C}^{2}$ App. The design cases were taken from some Examples in books that entitled Design of Reinforced Concrete $9^{\text {th }}$ Edition [20], and Reinforced Concrete Mechanics and Design $6^{\text {th }}$ Edition [15] for rectangular, and circular columns in short and slender conditions. The following is the summary of the design parameters used in each case :

Table 1. Column Cases 1

\begin{tabular}{ccccccc}
\hline Case & $\begin{array}{c}D \\
(\mathrm{~mm})\end{array}$ & $\begin{array}{c}P_{u} \\
(\mathrm{kN})\end{array}$ & $\begin{array}{c}M_{u \mathrm{x}} \\
(\mathrm{kNm})\end{array}$ & $\begin{array}{c}M_{u y} \\
(\mathrm{kNm})\end{array}$ & $\begin{array}{c}M_{l x} \\
(\mathrm{kNm})\end{array}$ \\
\hline \hline 1 & {$[20]$} & 28.58 & 1663.63 & 318.24 & - & - \\
2 & {$[20]$} & 25.40 & 2668.93 & 108.80 & - & - \\
3 & {$[20]$} & 34.20 & 1957.22 & 321 & 261.12 & - \\
4 & {$[15]$} & 25.40 & 1112.06 & 74.8 & 149.6 & - \\
5 & {$[15]$} & 19.05 & 1014.19 & 77.29 & - & 51.53 \\
6 & {$[20]$} & 28.58 & 2224.11 & 306.00 & - & - \\
7 & {$[20]$} & 31.75 & 7117.15 & 204 & - & - \\
\hline
\end{tabular}

From the cases listed in Table 1, the total cost of the design results using $\mathrm{ACI}$ diagram and $\mathrm{C}^{2} \mathrm{App}$ for rectangular and square sections were calculated and the values are presented in Figure 15. The total cost in both procedures were compared to get the saving values and are presented in figure 16.

Table 2. Cost Comparison of ACI Diagrams and $C^{2} \mathrm{App}$ Results

\begin{tabular}{|c|c|c|c|c|c|c|c|}
\hline & Case & $\begin{array}{c}h / H \\
(\mathrm{~mm})\end{array}$ & $b(\mathrm{~mm})$ & $n_{h} / n$ & $n_{b}$ & Cost & Saving \\
\hline \multirow{3}{*}{1} & Example & 508 & 355.6 & 2 & 3 & Rp 410,033 & - \\
\hline & $\mathrm{C}^{2}$ Rec. & 350 & 600 & 2 & 2 & Rp 354,490 & $13.5 \%$ \\
\hline & $\mathrm{C}^{2}$ Square & 500 & 500 & 2 & 2 & Rp 390,724 & $4.7 \%$ \\
\hline \multirow{3}{*}{2} & Example & 406.4 & 406.4 & 3 & 3 & Rp 409,189 & - \\
\hline & $C^{2}$ Rec. & 450 & 400 & 2 & 2 & Rp 292,840 & $28.4 \%$ \\
\hline & $\mathrm{C}^{2}$ Square & 450 & 450 & 2 & 2 & Rp 313,221 & $23.5 \%$ \\
\hline \multirow{3}{*}{3} & Example & 558.8 & 558.8 & 3 & 3 & Rp 753,458 & - \\
\hline & $C^{2}$ Rec. & 650 & 450 & 2 & 2 & Rp 500,258 & $44.8 \%$ \\
\hline & $\mathrm{C}^{2}$ Square & 550 & 550 & 2 & 2 & Rp 509,317 & $43.8 \%$ \\
\hline \multirow{3}{*}{4} & Example & 406.4 & 406.4 & 3 & 3 & Rp 409,189 & - \\
\hline & $\mathrm{C}^{2}$ Rec. & 400 & 400 & 2 & 2 & Rp 274,723 & $32.9 \%$ \\
\hline & $\mathrm{C}^{2}$ Square & 400 & 400 & 2 & 2 & Rp 274,723 & $32.9 \%$ \\
\hline \multirow{3}{*}{5} & Example & 406.4 & 406.4 & 2 & 3 & Rp 259,119 & - \\
\hline & $\mathrm{C}^{2}$ Rec. & 250 & 450 & 2 & 2 & Rp 174,913 & $32.5 \%$ \\
\hline & $\mathrm{C}^{2}$ Square & 400 & 400 & 2 & 2 & Rp 217,940 & $15.9 \%$ \\
\hline \multirow{2}{*}{6} & Example & 508 & - & 6 & - & Rp 429,995 & - \\
\hline & $\mathrm{C}^{2}$ Cir. & 550 & - & 4 & - & Rp 379,476 & $11.7 \%$ \\
\hline \multirow{2}{*}{7} & Example & 660.4 & - & 10 & - & Rp 817,272 & - \\
\hline & $\mathrm{C}^{2}$ Cir. & 700 & - & 8 & - & Rp 754,200 & $7.7 \%$ \\
\hline
\end{tabular}




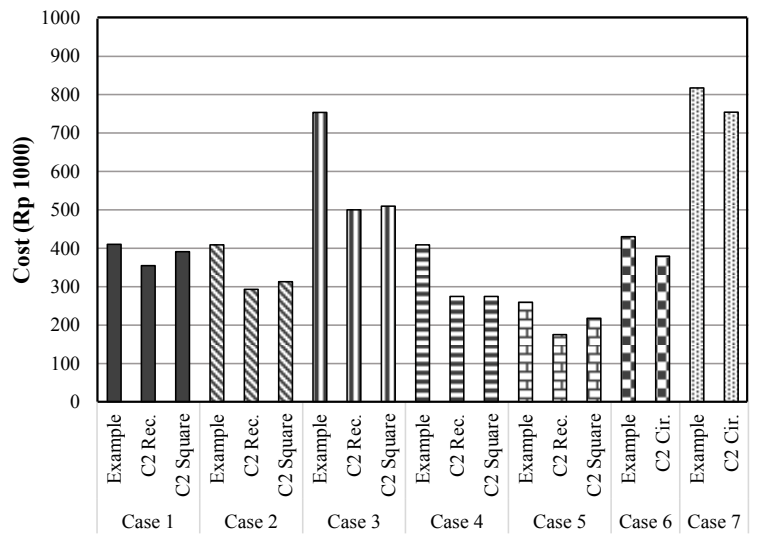

Fig. 15. Cost Comparison with ACI Diagrams Method

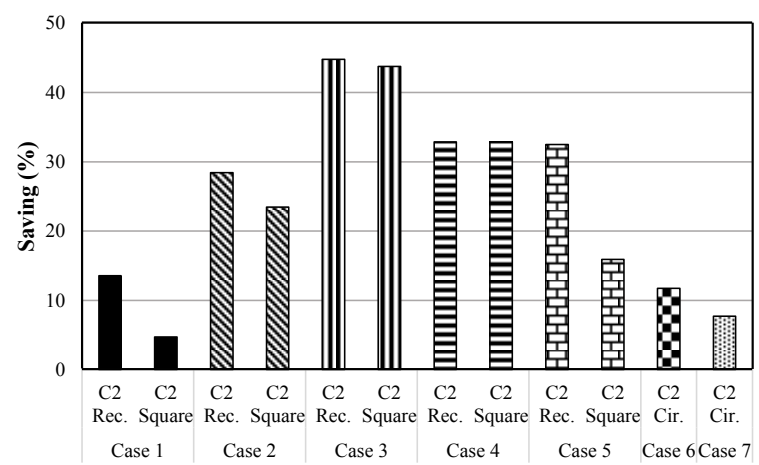

Fig. 16. Saving with ACI Diagrams Method

In all cases, it was found that $\mathrm{C}^{2} \mathrm{App}$ could produce more economical sections with saving averages of $30.4 \%$ for rectangular columns, $24.1 \%$ for square columns, and 9.7 $\%$ for circular columns.

\subsubsection{Particle Swarm Optimization}

Chutani, S. and Singh, J. (2016) had developed RC column optimization using Particle Swarm Optimization [2]. There were five cases of columns that had been designed with that method which then was compared with the optimization results using $\mathrm{C}^{2}$ App. The cases are presented in Table 3

Table 3. Column Cases 2

\begin{tabular}{cccc}
\hline Column & $P_{u}(\mathrm{kN})$ & $\begin{array}{c}M_{u} \\
(\mathrm{kNm})\end{array}$ & $\rho$ \\
\hline \hline 1 & 1100 & 230 & $0.8 \%$ \\
2 & 309 & 217 & $0.8 \%$ \\
3 & 283 & 85 & $0.8 \%$ \\
4 & 245 & 65 & $0.8 \%$ \\
5 & 100 & 32 & $0.8 \%$ \\
\hline
\end{tabular}

The column cases in Table 3 were optimized by using $\mathrm{C}^{2}$ App for rectangular and square sections. The results of these optimizations and Particle Swarm Optimization are presented Optimization in Table 4. Comparison of the total cost and saving percentage for each column are shown in Figures 17 and 18.

Table 4. Cost Comparison of Particle Swarm Optimization and $\mathrm{C}^{2}$ App Results

\begin{tabular}{llccccccc}
\hline \multicolumn{1}{c}{ Column } & $\begin{array}{c}h \\
(\mathrm{~mm})\end{array}$ & $\begin{array}{c}b \\
(\mathrm{~mm})\end{array}$ & $\begin{array}{c}D \\
(\mathrm{~mm})\end{array}$ & $n_{h}$ & $n_{b}$ & Cost & Saving \\
\hline \hline Paper & 780 & 300 & - & - & - & $\mathrm{Rp} \mathrm{331,840}$ & - \\
1 & $\mathrm{C}^{2}$ Rec. & 550 & 300 & 24 & 2 & 2 & $\mathrm{Rp} \mathrm{265,339}$ & $20.0 \%$ \\
& $\mathrm{C}^{2}$ Square & 450 & 450 & 24 & 2 & 2 & $\mathrm{Rp} \mathrm{299,308}$ & $9.8 \%$ \\
\hline & Paper & 780 & 300 & - & - & - & $\mathrm{Rp} \mathrm{331,840}$ & - \\
2 & $\mathrm{C}^{2}$ Rec. & 550 & 300 & 16 & 4 & 3 & $\mathrm{Rp} \mathrm{278,214}$ & $16.2 \%$ \\
& $\mathrm{C}^{2}$ Square & 450 & 450 & 16 & 4 & 4 & $\mathrm{Rp} \mathrm{337,934}$ & $-1.8 \%$ \\
\hline & Paper & 470 & 300 & - & - & - & $\mathrm{Rp} \mathrm{199,955}$ & - \\
3 & $\mathrm{C}^{2}$ Rec. & 300 & 300 & 16 & 2 & 2 & $\mathrm{Rp} \mathrm{133,026}$ & $33.5 \%$ \\
& $\mathrm{C}^{2}$ Square & 300 & 300 & 16 & 2 & 2 & $\mathrm{Rp} \mathrm{133,026}$ & $33.5 \%$ \\
\hline & Paper & 410 & 300 & - & - & - & $\mathrm{Rp} \mathrm{174,429}$ & - \\
4 & $\mathrm{C}^{2}$ Rec. & 350 & 200 & 14 & 3 & 2 & $\mathrm{Rp} \mathrm{122,554}$ & $29.7 \%$ \\
& $\mathrm{C}^{2}$ Square & 300 & 300 & 14 & 4 & 2 & $\mathrm{Rp} \mathrm{160,386}$ & $8.1 \%$ \\
\hline & Paper & 310 & 300 & - & - & - & $\mathrm{Rp} \mathrm{131,885}$ & - \\
5 & $\mathrm{C}^{2}$ Rec. & 300 & 200 & 14 & 2 & 2 & $\mathrm{Rp} \mathrm{93,780}$ & $28.9 \%$ \\
& $\mathrm{C}^{2}$ Square & 250 & 250 & 14 & 2 & 3 & $\mathrm{Rp} \mathrm{115,760}$ & $12.2 \%$ \\
\hline & & & & & & & \\
& & & & &
\end{tabular}

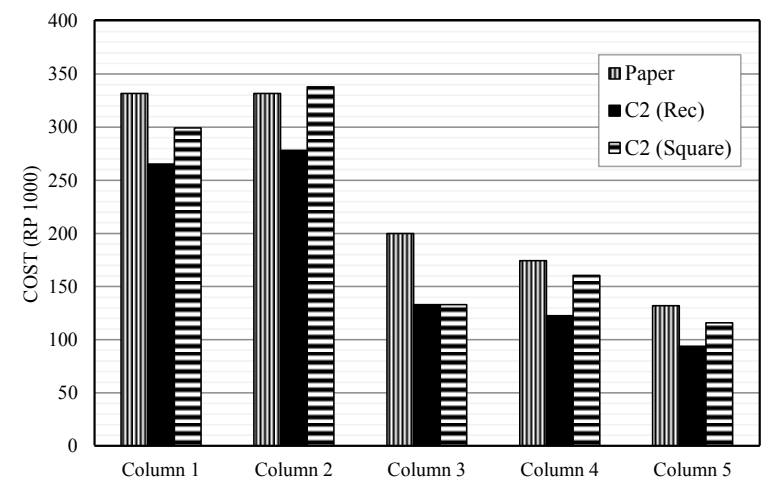

Fig. 17. Cost Comparison with Particle Swarm Optimization Method

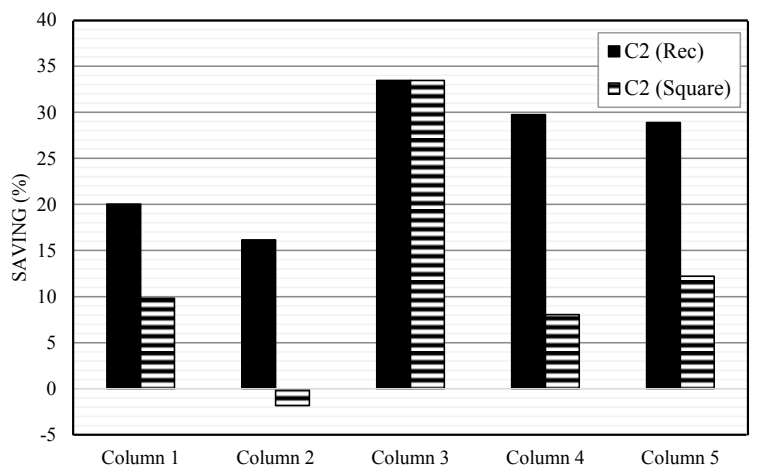

Fig. 18. Saving with Particle Swarm Optimization Method Figure 17 shows that the performance of both methods is quite competitive with 4 results show that the output of 
$\mathrm{C}^{2}$ App are more economical. At Column 2, the square section result from $\mathrm{C}^{2} \mathrm{App}$ has higher total cost than column resulted by Particle Swarm Optimization. Square column provides more uniform capacity in $\mathrm{X}$ and $\mathrm{Y}$ directions, so for uniaxial case it will results more extravagant section.

The use of rectangular section can possibly get a longer distance between the compressive force and the neutral axis so that the moment capacity increases. In addition, the reinforcement can also be arranged in such a way that it has longer lever arm to produce more capacity.

The total cost of RC column depends on the volume of concrete and the reinforcement. For the same capacity, column with wider section may not directly be the expensive one. Therefore, any combination of concrete and reinforcement needs to be evaluated to obtain an economical column section.

\section{Conclusions}

Optimization of RC column can be carried out by using Android-based mobile application. Variable values such as steel diameter, and the grades of concrete and steel can be inputted according to the real value which is available in the real condition so that the optimization can be more flexible, accurate, and faster. Optimization of RC column is highly dependent on the total cost of the cross-section obtained, where the total cost is the sum of the prices of concrete and reinforcement. The price of the material can be calculated according to the prevailed unit price of concrete and steel in an area, so the optimization can be adjusted based on each region. It also causes the result of $\mathrm{RC}$ column optimization in each region can be different. $\mathrm{C}^{2}$ App as Android-based mobile application was equipped with local database, so the optimization can be done in accordance with the name of the project, and also the name of each column in a project. In addition, this app was also equipped with export as pdf function which can generate a report that contains detail calculation of the column.

\section{References}

1. S. K. Dalton, S. Atamturktur, I. Farajpour, C. H. Juang, Eng. Struc. 57, 356-363 (2013)

2. J. Singh, S. Chutani, IJIET 5, 365-369 (2015)

3. R. Regupathi, IRJET 04, 888-896 (2017)

4. G. Sanchez-Olivares, A. Tomas, Eng. Struc. 130, 162-179 (2017)

5. M. Mahamida, M. Houshiarb, JoBE 18, 66-75 (2018)

6. M.Y. Rafiq, C. Southcombe, Comp. \& Struc. 69, 443-457 (1998)

7. A. Tapao, R. Cheerarot, Eng. Struc. 151, 802-820 (2017)

8. G. F. de Medeiros, M. Kripka, Eng. Struc. 59, 185194 (2014)

9. M. Aschheim, E. H. Montes, L. M. Gil-Martin, J. Struc. Eng 134, 231-239 (2008)

10. S. M. Thomas, G. P. Arulraj, IJRGG 10, 81-87 (2017)
11. F. A. Mohammad, D. A. Seyan, AJTE 3, 225-239 (2016)

12. A Guerra, and P. D. Kiousis, Comp. \& Con. 3, 313334 (2006)

13. T. A. Jabbar, IJAER 12, 2136-2149 (2017)

14. J. L. Bonet, P.F. Miguel, M.A. Fernandez, and M. L. Romero, J. Struct. Eng. 130, 2006-2015 (2004)

15. Wight, J. K., \& MacGregor, J. G., Reinforced Concrete Mechanics and Design $6^{\text {th }}$ Edition (2012)

16. Badan Standardisasi Nasional, SNI 2847: 2013 Persyaratan Beton Struktural untuk Bangunan Gedung (2013)

17. ACI Committee 318, Building Code (2011)

18. Bresler, B., JACI, 481-490 (1960)

19. W. H. Mosley, and J. H. Bungey, Reinforced Concrete Design (1982)

20. McCormac J. C. \& Brown R. H., Design of Reinforced Concrete $9^{\text {th }}$ Edition (2014) 